Proceedings

\title{
Influence of the Pump Control System in the Selection of the Number of Fixed Speed and Variable Speed Drive Pumps in Water Pumping Stations
}

\author{
Christian Briceño *, Pedro Iglesias and Javier Martinez \\ Department of Hydraulic Engineering and Environment, Universidad Politécnica de Valencia, 46022 \\ Valencia, Spain; piglesia@upv.es (P.I.); jmsolano@upv.es (J.M.) \\ * Correspondence: chbri1@alumni.upv.es ; Tel.: +34-963877610 \\ + Presented at the 4th International Electronic Conference on Water Sciences, 13-29 November 2019; \\ Available online: https://ecws-4.sciforum.net/.
}

Published: 12 November 2019

\begin{abstract}
Proper design of a pumping system requires the use of a pump curve and set-point curve system. Both have to be as close as possible to optimize energy use. This is achieved by control systems in which the type of control (flow or pressure) and the combination between fixed speed drive (FSD) pumps and variable speed drive (VSD) pumps are involved. The objective of this work is to determine the optimal number of FSD and VSD pumps for each flow rate range in order to discuss the classic design of pumping stations and their control systems. For this, a methodology is applied that defines the parametric form of the pump curve, efficiency curve, and set-point curve in relation to the most efficient point. In this way, dimensionless expressions are obtained and the influence of the set-point parameters on the design of the control system can be analyzed. Additionally, the method includes an expression that estimates the performance of the frequency inverter, which is based on the load and pump speed rotation. The application of the methodology to different case studies allows us to question many classic procedures for pumping stations. In summary, it can be concluded that the appropriate number of variable speed pumps for each control system cannot be established in advance but requires an in-depth study of different available options.
\end{abstract}

Keywords: pumping control system; set-point curve; best efficient point; variable speed driver

\section{Introduction}

Population growth and urban area size factor into how water distribution networks increase their water demand and requirements for pumping station energy usage. Therefore, it is important to optimize the operations of pumping stations in order to save energy [1]. In fact, approximately $95 \%$ of energy consumption is related to pumping energy costs, whereas approximately $90 \%$ of the pump lifecycle cost corresponds to operational costs that are closely related to energy consumption [2].

Pumping station efficiency is related to operational system sizing requirements such as pipelines size, flow demand, and the minimum head pressure required to satisfy node consumption. In fact, pump optimization can be achieved by changing the control system and establishing a new pump schedule that adds pumps in a parallel configuration with variable speed drivers (VSDs) and using flow and pressure controls [1].

Recently, research has examined pump scheduling with fixed speed pumps (FSPs) by using advanced mathematical models (i.e., evolutive algorithms) in order to optimize the reduction of energy consumption. This is done by controlling the frequency of starting and stoppings pumps, as shown by $\mathrm{Yu}$ et al. [3]. Similarly, Wu and Gao [4] use a multi-objective optimization in pumping 
stations, which includes energy costs, treatment costs, the minimization of the number of pump switches, and the maximization of the hydraulic service level.

Additionally, several other works have concluded that the use of VSDs in pumping stations can achieve better results in terms of reducing energy consumption. Planells et al. [5] and Lamanddalena and Khila [6] developed several control systems with VSDs. These mechanisms sought to configure the pumping station so that the head and flow values followed the system set-point curve. In this way, when the driving curve is closest to the resistant curve, the best energy savings are achieved. Moreover, Hashemi et al. [7] proposed a pump scheduling optimization cost with variable speed pumps (VSP) that uses an ant colony optimization model. Furthermore, Wu et al. [8] worked on a parallel pump optimization system that featured several VSD configurations and control valves in order to provide a suitable operating mode with a balance between pumping system efficiency and reliability.

Walsky and Creaco [9] developed a comparison between different pumping station configurations with fixed speed pumps (FSD pumps) and VSD pumps for a water distribution system without storage. They concluded that using more FSPs than the system required brings pumps closer to their best efficient point (BEP) and thus the operational costs are lower. Another benefit in terms of operational costs can be achieved in the configuration where large pumps are flanked by small pumps or by adding VSD in the pumping station, especially in cases with small flow demands.

For the proper design and dimension of a pumping station, it is necessary to use three curves: the set-point curve, the pump head curve, and the pump efficiency curve. The set-point curve and the head curve should be as close as possible to make sure that the pump curve achieves its BEP for optimal energy consumption. The set-point curve is defined as the minimum head required in a water source to satisfy the flow demand while the minimum pressure required at the critical consumed node of the network is guaranteed.

Celi et al. $[10,11]$ developed a methodology that optimizes the flow rate of multiple pumping stations in a closed water distribution network. This methodology is based on the use of the set-point curve as a reference for the pumping station control system in order to use the lowest amount of energy. Moreover, this study was extended to cases with storage tanks. In this case, we consider other parameters, such as the maximum and minimum water level in storage tanks [12].

To ensure that the pumping station curve is as close as possible to the set-point curve, different control systems have been considered. These control systems depend on two main factors: the type of pumps used (i.e., FSD pump, VSD pump) and the type of control that operates the pumps (i.e., pressure controls, flow controls). In the case of FSD pump, pressure controls are related to the pump's start and stop according to the pressure set levels (i.e., maximum pressure level stops the pumps and minimum pressure level starts the pumps). For FSD pump, flow controls are related to the pump's start and stop according to the demand flow. In the case of VSD pump, operation is more general since both types of controls not only determine the start and stop of the pumps but also the rotational speed of the pumps with VSDs [13].

In previous works, Celi et al. [10,11] optimized energy consumption by considering a theoretical constant minimum pump efficiency but did not consider the pump station design and which control system would operate the pumping station. Thus, the main objective of this study is to determine the influence that the number of VSD pumps used in a control system may have on operating costs.

\section{Methodology}

An optimized design of a pumping station requires that the driving curve (a consequence of the selection of the pumping groups and the control system) be as close as possible to the set-point curve. In this way the minimum energy consumption is achieved that satisfies the demands and water distribution network requirements [14]. To achieve this statement, different control strategies are used in water pumping stations. Consequently, the methodology of this paper is based on math formulations of the set-point curve, the head curve and the BEP of the pump in order to analyze the influence that the number of VSDs have on control systems in terms of saving energy in water pumping stations. 
The methodology consists of defining all the equations in a dimensionless form, taking as reference the values of the pump in the BEP. The variables flow $(Q)$, height $(H)$, speed of rotation $(N)$, efficiency $(\eta)$, power $(P)$ and torque $(M)$ are transformed into their dimensionless equivalents $(q, h, \alpha$, $\vartheta, \pi, \beta)$ :

$$
q=\frac{Q}{Q_{0}} ; h=\frac{H}{H_{0}} ; \alpha=\frac{N}{N_{0}} ; \theta=\frac{\eta}{\eta_{0}} ; \pi=\frac{P}{P_{0}} ; \beta=\frac{M}{M_{0}}
$$

In the previous Equation (1), variables with subscript 0 refer to the value in the BEP.

Usually pump curves and efficiency curves are expressed in a quadratic polynomial expression of three terms [15]. Nevertheless, in this methodology it is assumed that the head curve, efficiency curve and the set-point curve have a quadratic polynomial expression of two terms. When a pumping system has VSD, affinity laws are used in order to predict the operation points of the pump when the rotational speed varies with respect to its nominal point. Therefore, pump curves are the head curve and the efficiency curve using the affinity law are expressed as shown in Equations (2) and (3), while the set-point curve is expressed in Equation (4).

$$
\begin{aligned}
& H=A \cdot \alpha^{2}-B \cdot Q^{2} \\
& \eta_{b}=E \cdot \frac{Q}{\alpha}-F \cdot \frac{Q^{2}}{\alpha^{2}} \\
& H_{c}=\Delta H-R \cdot Q^{2}
\end{aligned}
$$

In the previous equations the terms $A$ and $B$ are constant parameters related to the characteristic of the model pump $E$ and $F$ are constant parameters of the efficiency curve and the terms $\Delta H$ and $R$ are parameters related to the set-point curve. $\Delta H$ is related to the minimum pressure required and $R$ refers to the losses produced in the water distribution network. Besides, the term A of Equation (2) corresponds to the maximum head of pump. For the development of this formulation, it is admitted that $\mathrm{A}$ is $4 / 3$ of the nominal head pumping $\left(H_{0}\right)$ [16]. Another assumption of the methodology is that pumping flow $(Q)$ is at its maximum when the head $(H)$ and the efficiency $(\eta)$ of the pump are 0 . If the derivative of Equations (2) and (3) is solved in the function of the flow $(Q)$, it is shown that maximum flow $\left(Q_{\max }\right)$ is two times the nominal flow $\left(Q_{\max }=2 Q\right)$. If Equations (2)-(4) are represented in a parametric form in relation to the BEP, the pump curve, the set point curve and the efficiency curve are established in a dimensionless form as is showed in the following expressions (5), (6) and (7).

$$
\begin{aligned}
& h=\frac{4}{3}-\frac{1}{3} \cdot q^{2} \\
& \theta=2 \cdot q-q^{2} \\
& h_{C}=\lambda+r \cdot q^{2}
\end{aligned}
$$

In the above Equations (8) and (9), $\lambda$ and $r$ represent the reduced form of parameters $\Delta H$ and $R$.

$$
\begin{gathered}
\lambda=\frac{\Delta H}{H_{0}} \\
r=\frac{R \cdot Q_{o}^{2}}{H o} \\
\pi=\frac{q \cdot h}{\theta}
\end{gathered}
$$

Additionally, the expressions for the power $(\pi)$ and for the mechanical torque $(\beta)$ of the pump can be written in reduced variables as is expressed in Equation (11):

$$
\pi=\frac{q \cdot h}{\theta}=\beta \cdot \alpha
$$


It is important to remember that the aim of a proper pumping station design consists of ensuring a minimum required pressure at every node in the system. In fact, the pumping head pressure must be equal to the minimum head pressure required in the network for every flow range.

This methodology has been based on the operation of a control system equipped only with VSD pumps and regulated with pressure and flow controls. The regulation mode with VSP is based on a continuous modification of the rotational speed of the pumps in order that the pumping system follows the set-point curve. If fact, the pumping system is measured with flow and pressure controls and these variables are constantly sent to the programmable logic controller (PLC). This device does a comparison between the measured variables and the previously set variables $(Q$ and $H)$ of the setpoint curve for every time step defined and finally the PLC sends orders to the pumping system so the rotational speed of the pumps changes [17].

Figure 1 represents a classic control system configuration with VSP. The number of VSD pump determines the number of operational ranges $\left(Q_{1} ; Q_{2} ; Q_{n}\right.$ and $\left.Q_{\max }\right)$. The terms $\left(Q_{1} ; Q_{2} ; Q_{n}\right)$ represent the maximum flow that one, two or $n$ VSD pumps respectively supplies the system maintaining the head required pressure of the set-point curve, while $Q_{\max }$ represents the maximum demand flow of the system. In this way, when demand flow $(Q)$ is lower than $Q_{1}$, only one VSD pump operates at $N$ rotational speed. On the other hand, when $Q$ is in the range between $\left(Q_{1}<Q<Q_{2}\right)$, a second VSD pumps starts to operate at $(N)$ rotational speed and the first VSD pump operates at the nominal speed $\left(N_{0}\right)$. Finally, when $Q$ is in the last range between $\left(Q_{2}<Q<Q \max \right)$, the third pump starts to operate at $(N)$ rotational speed, and the other pumps operate at the nominal speed $\left(N_{0}\right)$. The presented methodology discusses this classical mode regulation. Thus, this study is focused of the first operational range that corresponds from $\left(0<Q<Q_{1}\right)$. The objective of this work is to determine the optimal number of VSP over the range studied so that the consumed energy is optimal.

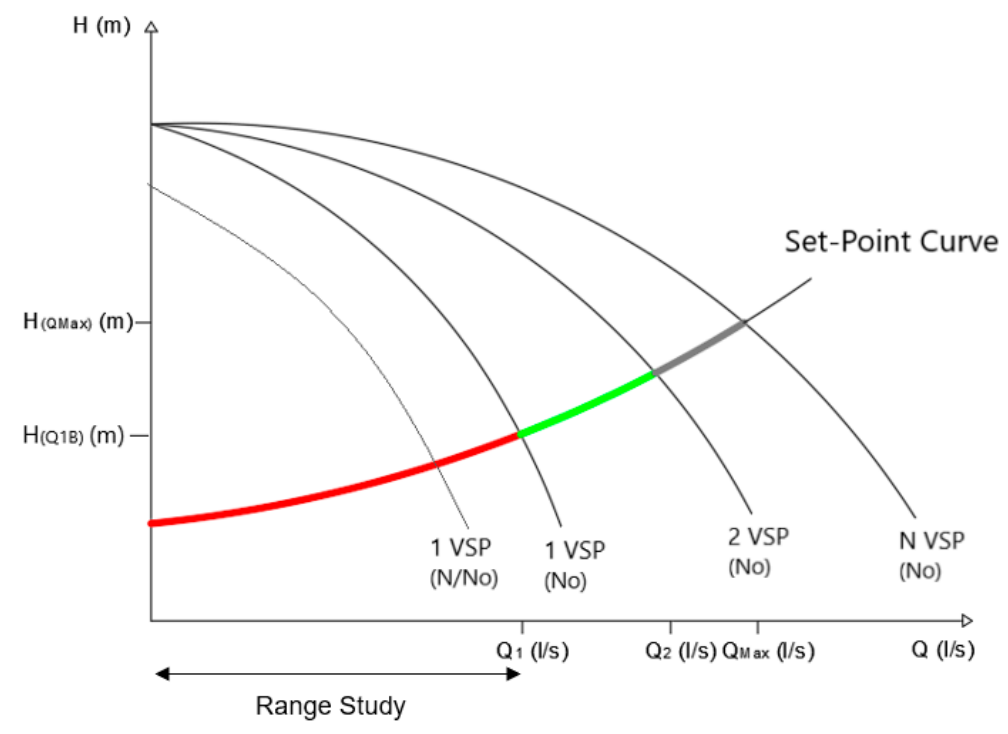

Operation of parallel VSD pump configuration

Figure 1. Operation squeme of parallel VSD pumps following the set-point curve with pressure and flow controls.

The process of this methodology consists of proving different configurations of VSD pumps. In every proof is added an additional VSD pumps until the optimal energy is achieved in every flow step. The dimensionless power of the pumping system is calculated for every pumping configuration proved in the study range. The decision variables of this study are the dimensionless terms of the setpoint curve and the BEP of the pump.

If the pump head in a parametric form $(h)$ in the Equation (5) is equal to head system in a parametric form $\left(h_{c}\right)$ in the expression (7), the following equations are obtained. 


$$
\begin{gathered}
q_{b 1}=\sqrt{\frac{4-3 \cdot \lambda}{3 \cdot r+1}} \\
\alpha_{n}=\sqrt{\frac{3 \cdot \lambda+\left(3 \cdot r+\frac{1}{n^{2}}\right) \cdot q^{2}}{4}} \\
\pi_{n}=\frac{\alpha^{2}}{3}(2 \cdot \alpha \cdot n-q)
\end{gathered}
$$

where $q_{b 1}$ in Equation (9) is defined as the maximum flow of the pump at its nominal rotational speed (No) that supplies the system maintaining the minimum head pressure required in the set-point curve. The term $\left(\alpha_{n}\right)$ in Equation (10) is defined as the rotational speed of each pump that operates in order to follow the head of the set-point curve, $n$ represents the number of the VSD pumps operating and $\pi_{n}$ in Equation (11) is the reduced power that is in relation to the nominal power of the pump $\left(P_{0}\right)$.

Even though, is usually to use the affinity lows to estimate the efficiency of the pumping system, this approximation can have imperfections in the results of the efficiency pump, especially when the rotational speed has low values. When the rotational speed of the pump decreases in relation to the nominal rotational speed, the BEP of the pump is affected and it decrease too, as is described in Simpson and Marchi's work [19] (Figure 2). Thus, this methodology has also used the formula proposed by Sarbu and Borza [18] that corrects these imperfections. It is shown in the following expression (12) and (13).

$$
\begin{aligned}
& \eta_{2}=1-\left(1-\eta_{1}\right) *(1 / \alpha)^{0.1} \\
& \theta_{2}=1-\left(1-\theta_{1}\right) *(1 / \alpha)^{0.1}
\end{aligned}
$$

where $\eta_{2}$ corresponds to the real efficiency of the variable speed pump and $\eta_{1}$ is the estimate efficiency by the affinity lows and the expression (13) is the same expression as the previous one but in a reduced form.

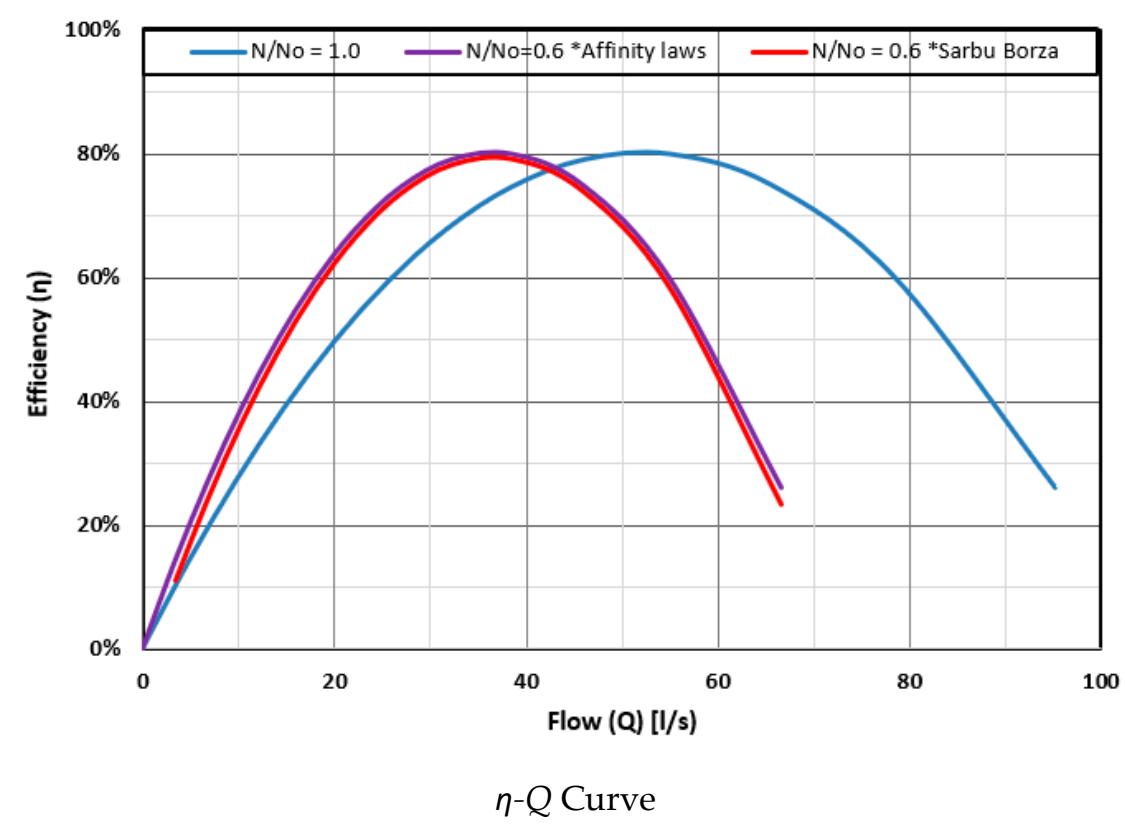

Figure 2. Comparison of the affinity laws and the Sarbu Borza expression when the rotational speed of the pump change.

VSD is an electrical device in the pumping system that controls the motor speed and torque. This device converts the simi-wave power from the power supply into the variable frequency power and sent to the motor, where it finally converts the variable frequency power into the mechanical power 
and this process generate some losses [20]. Therefore, the efficiency of the variable speed driver is defined as the relation between the input power to the motor and the input power of the variable speed drive.

Another aim of this methodology is to define an expression that allows to estimate the performance of this device. The expression is obtained as the result of adjusting a curve to laboratory tests of VSD taken of Europump work [21] as is shown in the Figure 3. These tests consist of measuring the efficiencies with different combinations of rotational speed and the load of the motor, where the frequency or the rotational speed are kept constant and the load of the motor is changed.

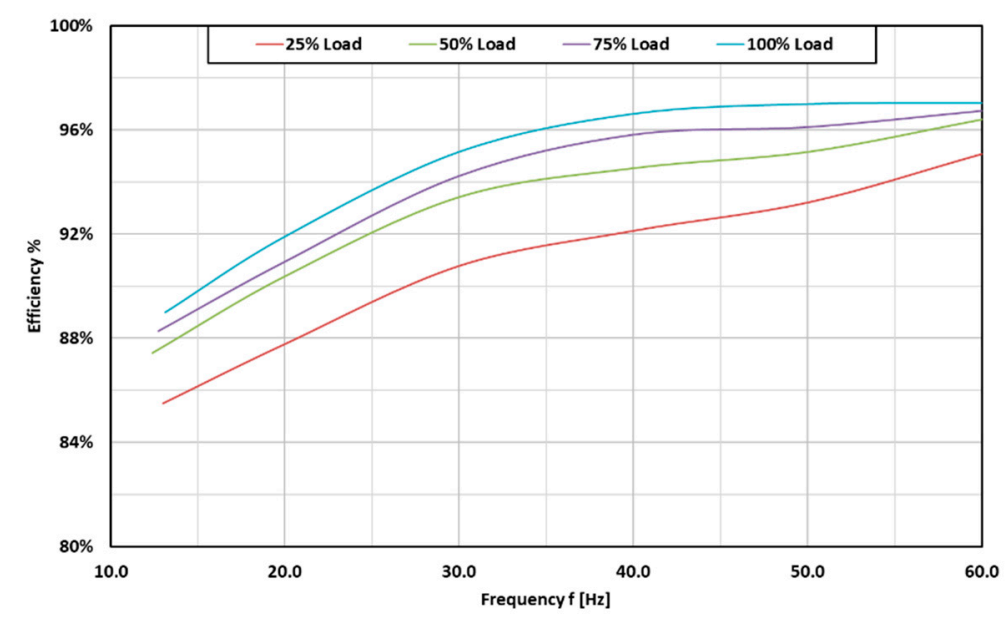

Efficiency-Frequency curve of VSD

Figure 3. Laboratory test results of VSD performance (Source: Europump and Hydraulic Institute 2004).

The VSD efficiency is the defined as the following Equations (14) and (15).

$$
\begin{gathered}
\eta_{V}=\eta o_{V} *\left[\beta_{V}^{0.0253}-0.1 *(1-\alpha)^{2.705}\right] \\
\beta_{V}=\frac{3}{4} * \frac{\Pi}{\alpha}
\end{gathered}
$$

where $\eta_{V}$ is the performance of the VSD, $\beta_{V}$ is the dimensionless load of the VSD in relation to the optimal load and the $\beta_{V}$ is also defined as $4 / 3$ of the maximum load of the motor $(\beta o)$.

Once, the use of the affinity laws, Sarbu and Borza formulation and the VSD efficiency are defined, the operation of a VSP can be determined in a better approximately way in order to analyze the influence of the number of VSDs has over the regulation mode.

The reduced power for every number of VSPs is analyzed by different combinations of terms $\lambda$ and $r$. When the minimum head required pressure of the system $(\Delta H=0)$, the term $\lambda$ gets its minimum value $(\lambda=0)$. On the other hand, the maximum value of $\Delta H$ can be the maximum head of the pump, so the maximum value of $(\lambda=1)$ where, the minimum and maximum value of losses $(r)$ in the system are assumed as 0 and 1 respectively. 


\section{Case Study}

A schematic water distribution network named EX Network (figure 4) has been defined to apply the proposed methodology. This network has one pumping station equipped with four VSPs and supplying three consumer nodes. The values of its elements are represented in the Table 1.

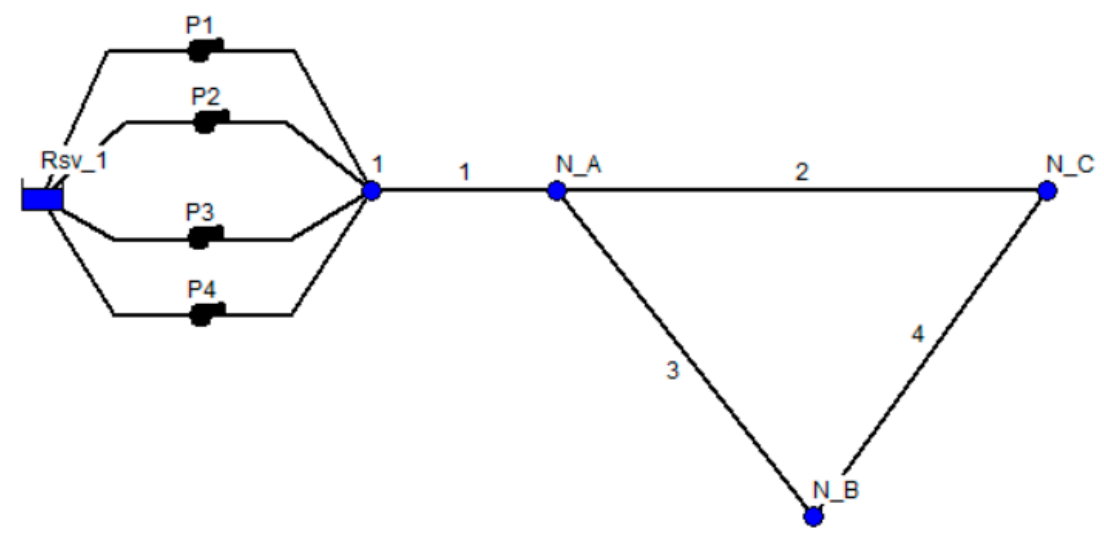

Network example

Figure 4. Scheme of the example network.

Table 1. Information of nodes and pipelines of the network example.

\begin{tabular}{ccccccc}
\hline I. Node & Elev $(\mathbf{m})$ & F. Node & Elev $(\mathbf{m})$ & Pipe & Diameter $(\mathbf{m m})$ & Length $(\mathbf{m})$ \\
\hline Rsv 1 & 105 & 1 & 105 & PUMP & & \\
1 & 105 & NA & 100 & 1 & 700 & 5000 \\
NA & 100 & NB & 102 & 3 & 400 & 1000 \\
NB & 102 & NC & 105 & 4 & 250 & 3000 \\
NC & 105 & NA & 105 & 2 & 300 & 3000 \\
\hline
\end{tabular}

A pump manufacturer model has been set to analyze the pumping control system. The BEPs of this pump have the following values: optimal flow $\left(Q_{0}=85.5 \mathrm{l} / \mathrm{s}\right)$, optimal head $\left(H_{0}=52.5 \mathrm{~m}\right)$ and maximum efficiency $\left(\eta_{\max }=83 \%\right)$, so the head pump curve and efficiency curve are defined as Figure 5 and Figure 6. A certain set-point curve is also represented in Figure 5.

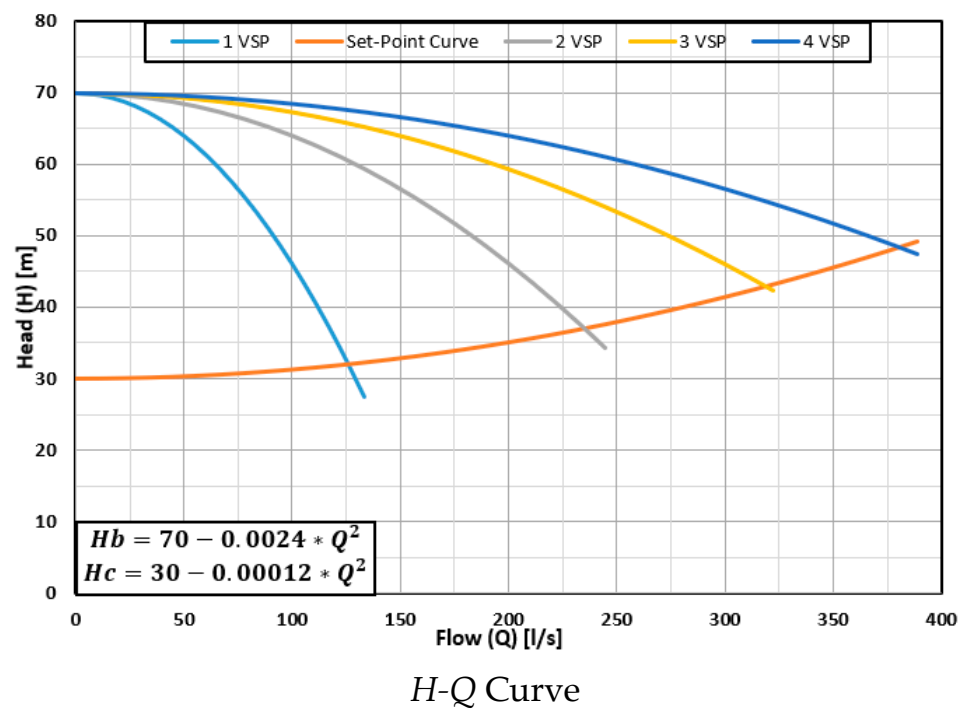

Figure 5. Corresponds to the model pump of the $H-Q$ curves and the set-point curve of the system. 


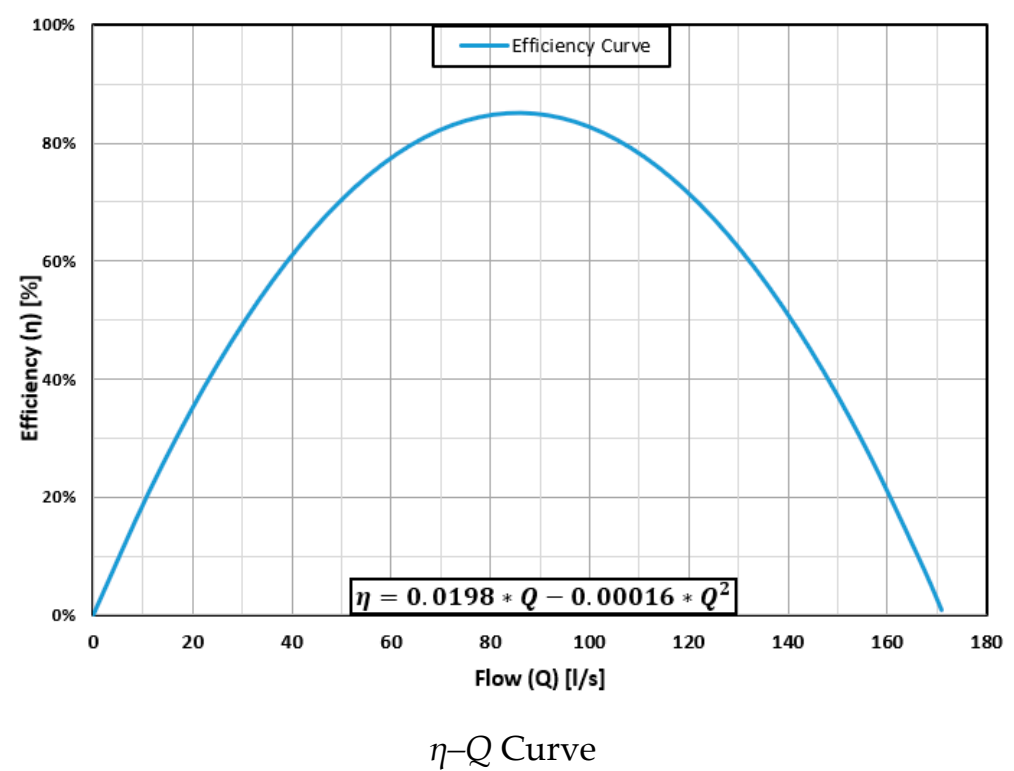

Figure 6. Represents the efficiency curve of the model pump.

In the study, the range $(0<\mathrm{q}<\mathrm{qb} 1)$ has been evaluated for the reduced power $(\pi)$ of four different pumping configurations that are: (OFSP-1VS), (OFSP-2VS), (OFSP-3VSP) and (0FSP-4VSP). The results are summarized in Figure 7.

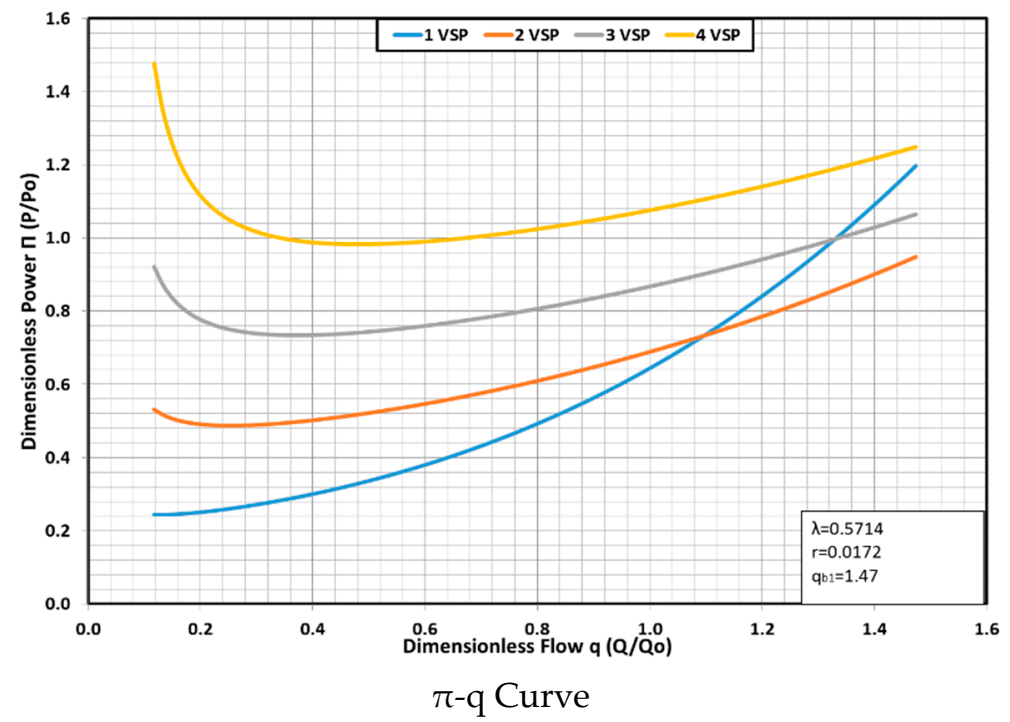

Figure 7. Dimensionless power $(\pi)$ for every number of VSPs in the flow range studied $\left(0<\mathrm{q}<\mathrm{q}_{\mathrm{b}}\right) . \lambda$ and $r$ are the terms of the set-point curve in a parametric form and are the decision variables of the analysis to evaluate consumed power in the pump station.

The term of $q_{b 1}$ of the pump is 1.47 (Figure 7). This means that the maximum flow of one VSP is greater than the nominal flow. On the other hand, the reduced terms of the set-point curve are $(\lambda=$ $0.57)$ and $(r=0.0172)$. In these conditions, it can be said that the best solution energy terms do not always use one VSP. In fact, when the flow $(\mathrm{q})$ is in the range $(1.1<q<1.47)$, the optimal configuration is two VSPs operating.

In order to know how the parameters of the set-point curve affect the optimal number of VSPs in a regulation mode, two different combinations of $\lambda$ and $\mathrm{r}$ in the pumping system have been set. The first combination is $(\lambda=0.5 ; r=0.5)$ and the second combination is $(\lambda=0.3 ; r=0.01)$. The results are reported in the following Figures 8 and 9. 


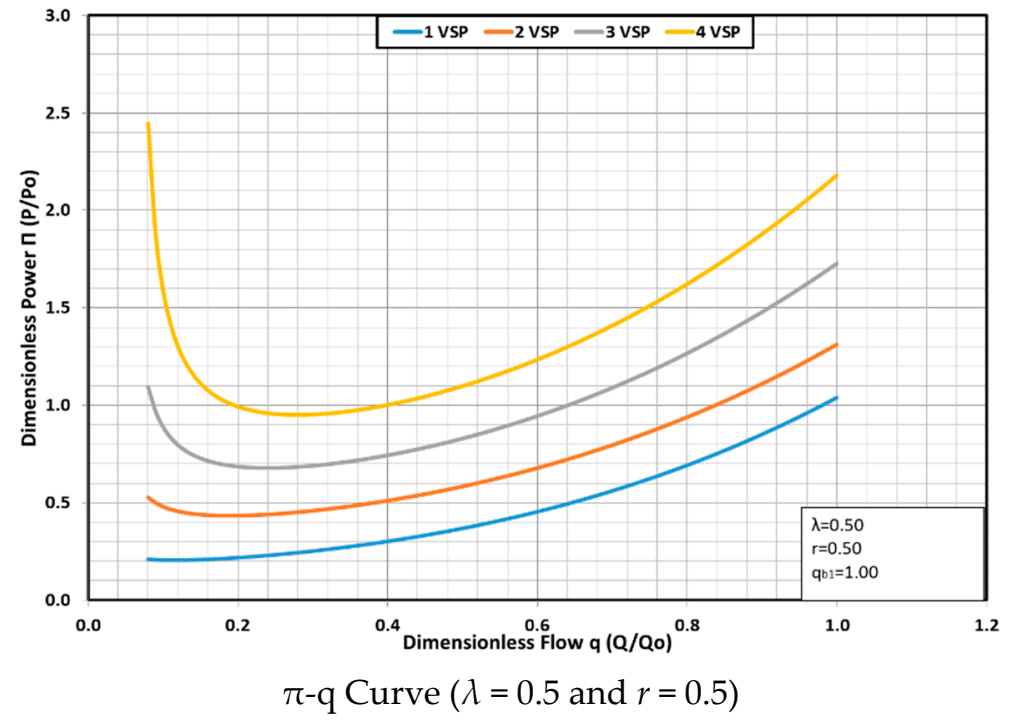

Figure 8. First combination of set-point parameters $(\lambda=0.5$ and $r=0.5)$.

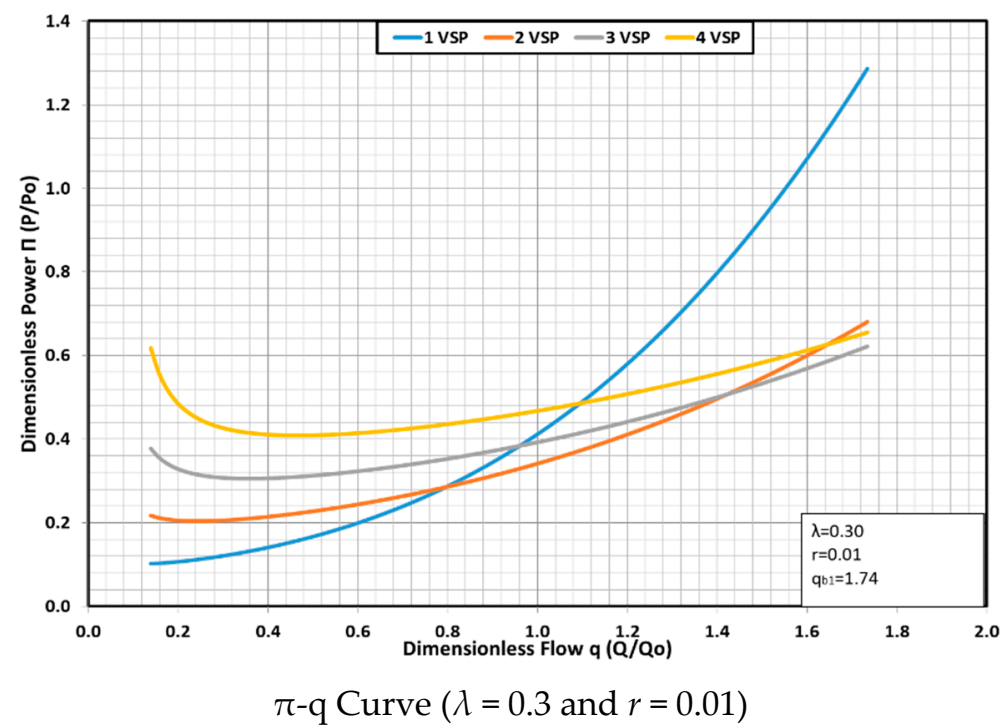

Figure 9. Second combination of set-point parameters $(\lambda=0.3$ and $r=0.01)$.

Figures 8 and 9 shows that it has set two different combination of decision variables of the setpoint curve that are $\lambda$ and $r$. The first combination $(\lambda=0.5 ; r=0.5)$ gets a value of $\left(q_{b 1}=1\right)$, while the second combination $(\lambda=0.3 ; r=0.01)$ gets a value of $\left(q_{b 1}=1.73\right)$.

In the first combination of set-point variables, always one VSD pump operating is the best option so that the consumed energy be optimal as it can be evidenced in the Figure 8. In contrast, in the second case (Figure 9), where $\mathrm{qb}_{\mathrm{b}}$ is greater than the optimal flow $(q=1)$. There are three adequate pumping configurations. When q is between $(0<q<0.8)$, one VSP operating is the best configuration. When $\mathrm{q}$ is between $(0.8<q<1.42)$, the best pumping configuration is with two VSD pumps operating. Finally, when the demand flow is between $(1.42<q<q b 1)$, three VSD pumps operating get the best results of consumed energy.

When $\mathrm{q}_{\mathrm{b} 1}$ is equal or lower than the nominal flow $\left(Q_{0}\right)$, the best selection of pumping configuration is always with one VSP in operation. Even though when qb is greater than the nominal flow $\left(Q_{0}\right)$ or $\left(q_{b 1}>=1\right)$, more than one VSP in operation would have better results in energy terms

The parameters of the set-point curve $(\lambda$ and $r$ ) have a great influence in the selection of the optimal number of VSD pumps in pumping control systems in order to obtain the optimal consumed energy. In fact, as $\lambda$ and $r$ have lower values, more than one VSD pump in operation could be optimal. The dimensionless terms ( $\lambda$ and $r$ ) are related with the size of the pumps and the generated losses in 
the network. As a result, $\mathrm{q}_{\mathrm{b} 1}$ have greater values if the system has low losses $(r)$ or when the selectioned pump has more capacity. On the other hand, the values of $q_{b 1}$ decrease as the losses are greater or as the selectioned pump is smaller.

In summary, when the water distribution network has lower losses or in other words when the set-point curve is flat and when the selectioned pumps have more capacity in terms of flow, the optimal number of VSPs operating would be more than only one pump in the range studied $(0<q<q b 1)$.

\section{Conclusions}

A methodology to analyze the optimal number of VSD pumps that consume the lowest energy in a parallel VSPs configuration has been developed. Besides, a correction of the inaccuracy for affinity laws and its effect on the VSD efficiency has been included in the analysis.

There are numerous possibilities of adequate configuration on control systems with VSD pumps to obtain the optimal consumed energy in the range studied $(0<q<q b 1)$. These possibilities depend on the capacity of the pumps (small pumps or large pumps) and the losses of the network. If the pumps have a large capacity and the slopes of the set-point curve have lower values, there would be several optimal numbers of VSPs in the range studied.

In general, for low flows in the range studied the optimal number of VSD pumps is one pump in operation. However, as the flow increases in the range studied, the optimal number of VSD pumps would be more than one pump, especially when $\mathrm{q}_{\mathrm{b}}$ is greater than the nominal flow $\left(Q_{0}\right)$.

The present study proves that not always one VSP operating is the optimal in energy terms as the classic method states in parallel VSPs configuration, so it requires a depth analysis of the parameters of the pump and the set-point curve parameters to determine the optimal number of VSPs in the range flow.

It is important to mention that this proposed methodology can be applied for the next range flows $\left(q_{b 1}<q<q_{b 2}\right)$ and $\left(q_{b 2}<q<q_{\max }\right)$ as it showed in the Figure 1. Besides, this study can be extended including operational costs and investment costs in pumping stations.

Conflicts of Interest: The authors declare no conflict of interest.

\section{References}

1. Leiby, V.M.; Burke, M.E. Energy Efficiency Best Practices for North American Drinking Water Utilities; Water Research Foundation: Denver, CO, USA, 2011.

2. Frenning, L. Pump Life Cycle Costs: A Guide to LCC Analysis for Pumping Systems; Hydraulic Institute, Europump, U.S. Department of Energy's Office of Industrial Technologies: Washington, DC, USA, 2001.

3. Yu, G.J.; Powel, R.S.; Sterling, M. Optimized Pump Scheduling in water distribution systems. J. Optim. Theory Appl. 1994, 83, 463-488.

4. Wu, W.G.J. Enhancing the Reliability and Security of Urban Water Infrastructures through Intelligent Monitoring, Assessment, and Optimization. In Intelligent Infrastructures; Springer: Dordrecht, Germany, 2010; pp. 487-516.

5. Alandi, P.P.; Pérez, P.C.; Álvarez, J.F.O.; Hidalgo, M.Á.M.; Martín-Benito, J.M.T. Pumping Selection and Regulation for Water-Distribution Networks. J. Irrig. Drain. Eng. 2005, 131, 273-281.

6. Lamaddalena, N.; Khila, S. Efficiency-driven pumping station regulation in on-demand irrigation systems. Irrig. Sci. 2013, 31, 395-410.

7. Hashemi, S.S.; Tabesh, M.; Ataeekia, B. Ant-colony optimization of pumping schedule to minimize the energy cost using variable-speed pumps in water distribution networks. Urban Water J. 2014, 11, 335-347.

8. Wu, P.; Lai, Z.; Wu, D.; Wang, L. Optimization Research of Parallel Pump System for Improving Energy Efficiency. J. Water Resour. Plan. Manag. 2014, 141, 04014094.

9. Walski, T.; Creaco, E. Selection of Pumping Configuration for Closed Water Distribution Systems. J. Water Resour. Plan. Manag. 2016, 142, 04016009, .

10. León-Celi, C.; Iglesias-Rey, P.L.; Martínez-Solano, F.J.; Mora-Melia, D. A methodology for the optimization of flow rate injection to looped water distribution networks through multiple pumping stations. Water (Switzerland) 2016, 8, 575. 
11. León-Celi, C.F.; Iglesias-Rey, P.L.; Martínez-Solano, F.J.; Savic, D. Operation of Multiple Pumped-Water Sources with No Storage. J. Water Resour. Plan. Manag. 2018, 144, 04018050.

12. León-Celi, C.; Iglesias-Rey, P.L.; Martínez-Solano, F.J.; Savic, D. Pumping Cost Optimization in Looped Water Networks with Storage Capacity through the Searching of the Set-point Curve. In Computing and Control for the Water Industry CCWI 2017; CCWI: Sheffield, UK, September 2017.

13. Fuertes, V.; Serra, J.G.; Marcet, E.C.; Alemany, V.E.; Martinez, F. Estaciones de Bombeo y Regulación de los Sistemas Hidráulicos (Capitulo 19); Ingeniería Hidráulica Aplicada a los Sitemas de Distribución de agua: Valencia, Spain, 2009.

14. León-Celi, C.F. Optimization of both Energy Use and Pumping Costs in Water Distribution Networks with Several Water Sources Using the Set-point Curve. Ph.D. Thesis, Polythetic University of Valencia, Valencia, Spain. 2018.

15. Alemany, E.; de Leonardo, C.G.; Jiménez, L. Las Bombas y su Comportamiento (Capitulo 4); Ingenieria Hidraulica Aplicada a los Sistemas de Disstribución del Agua: Valencia, Spain, 2009.

16. Rossman, L.A. EPANET 2 User's Manual, Cincinnati, U.S.A; 2000, Environmental Protection Agency (EPA).

17. Alzamora, F.M.; Fuertes-Miquel, V.; Sancho, H. Estaciones de Bombeo de Inyección Directa a Red; En Ingenieria Hidraulica Aplicada a los Sistemas de Distribución de Agua, Unidad Docente de Mecánica de Fluidos, Universidad Politecnica de Valencia: Valencia, Spain, 2009; pp. 937-966.

18. Sarbu, I.; Borza, I. Energetic Optimization of Water Pumping in Distribution Systems. Period. Polytech. Mech. Eng. 1998, 42, 141-152.

19. Simpson, A.R.; Marchi, A. Correction of the EPANET inaccuracy in computing the efficiency of variable speed pumps. J. Water Resour. Plann. Manag. 2013, 139, 456-459.

20. Grupo WEG. Motores de Indução Alimentados por Inversores de Frequência PWM; Jaraguá do Soul, Brasil, 2016.

21. Europump \& the Hydraulic Institute. Variable Speed Pumping. In A Guide to Successful Applications; Elsevier: Great Britain, UK, 2004; p. 170. 